\title{
Definições terminológicas negativas: um mal necessário?
}

DOI: http://dx.doi.org/10.21165/el.v50i2.2944

\section{Ivanir Azevedo Delvizio' \\ Francine de Assis Silveira²}

\section{Resumo}

As convenções sobre elaboração de definições terminológicas, em geral, recomendam evitar o uso de estruturas negativas sempre que possível. Com isso, as definições negativas têm sido pouco ilustradas e discutidas. O objetivo deste artigo é analisar um conjunto desse tipo de definição e observar os casos em que pode ser utilizado. Para tal, fundamentou-se nos preceitos teóricos da Terminologia (CABRÉ, 1993; FINATTO, 2003; KRIEGER; FINATTO, 2004; BARROS, 2004; ALMEIDA; PINO; SOUZA, 2007; GALDIANO; ZAVAGLIA, 2015; SAGER, 1993; BARITÉ, 2017). Foram analisadas definições negativas utilizadas tanto no discurso especializado quanto em trabalhos terminográficos em diferentes áreas de especialidade. Observou-se que as definições negativas foram usadas para definir termos que expressam conceitos que têm como traço principal a ausência de uma característica, com valor negativo, que apresentam formantes negativos em suas estruturas, ou que mantêm relação de oposição com outro(s) termo(s), distinguindo-se dele(s) pela ausência de uma característica.

Palavras-chave: terminologia; definição terminológica; definição negativa.

1 Universidade Estadual Paulista "Júlio de Mesquita Filho" (UNESP), Rosana, São Paulo, Brasil; ivanir.delvizio@unesp.br; https://orcid.org/0000-0003-4359-7743

2 Universidade Federal de Uberlândia (UFU), Uberlândia, Minas Gerais, Brasil; francine.silveira.ufu@hotmail.com; https://orcid.org/0000-0002-3962-3972 


\title{
Negative terminological definitions: a necessary evil?
}

\begin{abstract}
Terminology definition conventions generally recommend avoiding the use of negative structures whenever possible. Therefore, negative definitions (ND) have been little illustrated and discussed. This paper aims to analyze a set of such definitions and observe in which cases they may be used. In roder to do so, the theoretical precepts of Terminology were studied (CABRÉ, 1993; FINATTO, 2003 ; KRIEGER; FINATTO, 2004; BARROS, 2004; ALMEIDA; PINO; SOUZA, 2007; GALDIANO; ZAVAGLIA, 2015; SAGER, 1993; BARITÉ, 2017). Negative definitions used both in specialized discourse and in terminographic works in different specialty areas were analyzed. Negative definitions were used to define terms that express concepts whose main feature is the absence of a characteristic with a negative value, concepts having negative formants in their structures, or having an oppositional relationship with another term, or terms, distinguished from one another by the absence of one characteristic.
\end{abstract}

Keywords: terminology; terminological definition; negative definition.

\section{Introdução}

As definições terminológicas costumam ser elaboradas segundo um conjunto de convenções lexicográficas e diretrizes terminológicas amplamente aceito. Por meio de uma revisão de literatura sobre o tema, é possível observar que existe uma convergência entre as recomendações feitas por diversos autores ao longo do tempo, dos clássicos aos contemporâneos, especialmente a orientação de que as formas negativas devem ser evitadas.

Entretanto, no que se refere a esta orientação, observou-se que, na prática terminográfica, por vezes, faz-se necessário recorrer à definição negativa para melhor explicar os conceitos expressos por determinados termos. Diante disso, considerou-se uma contribuição importante reunir alguns exemplos de definições negativas no sentido de observar em que casos elas seriam pertinentes.

Este artigo é também uma tentativa de revisar nosso próprio posicionamento diante do tema, questionando o status da definição negativa de "defeito a ser evitado" e considerando-a simplesmente um tipo de definição, dentre tantos outros, do qual o terminólogo pode fazer uso em situações específicas.

Para tanto, foi compilado um conjunto de definições terminológicas negativas, estudadas e/ou elaboradas por diferentes autores, com o intuito de delinear os casos em que elas seriam, sim, adequadas. 
O artigo está organizado em duas seções. Na primeira, "A definição negativa", é apresentada uma revisão teórica sobre a "definição negativa" no âmbito da Terminologia. Na segunda, "Definições terminológicas negativas" são apresentadas as análises: na subseção "No discurso especializado", é analisado um conjunto de definições elaboradas por diferentes organismos em diferentes áreas do discurso especializado: astronomia (UIA, 2006 apud BARITÉ, 2017), farmácia (ANVISA apud GALDIANO; ZAVAGLIA, 2015), turismo (BRASIL, 2006), saúde (ONU, 1946); em seguida, na subseção "Em trabalhos terminográfıcos", é analisado um conjunto de definições de diversas áreas elaboradas em trabalhos terminográficos: engenharia de materiais (ALMEIDA; PINO; SOUSA, 2007), dermatologia (BARROS, 2004) e turismo (DIAS, 2018; SANTOS, 2016; PEREIRA; DELVIZIO; BUENO, 2019). Com base nas duas subseções de análises, buscou-se sistematizar, a título de conclusão, os casos em que seria adequado utilizar formas negativas em uma definição terminológica.

\section{A definição negativa}

A elaboração de definições pode ser orientada por três abordagens de naturezas distintas: a abordagem lexicográfica (que descreve os diversos sentidos e usos das palavras na língua geral), a abordagem terminológica (que descreve o sentido dos termos em um domínio de especialidade) e a abordagem enciclopédica (que descreve referentes com informações de diversas naturezas), que podem, inclusive, estar sobrepostas.

A definição lexicográfıca e a definição terminológica, guardadas suas diferenças, possuem, na verdade, muitos pontos em comum, compartilhando um conjunto de recomendações sobre como elaborá-las e sendo estudadas segundo tipologias de definição muito próximas.

De acordo com Sager (1993), existem vários tipos de definição; estes devem ser utilizados conforme a natureza do conceito a ser definido e conforme a finalidade específica da definição. Assim, uma teoria mais adequada deveria admitir variadas possibilidades de definição, tanto para a Lexicografia quanto para a Terminologia.

Embora no paradigma atual dos estudos terminológicos compreenda-se que "cada ciência ou área de conhecimento pode exibir um padrão textual definitório que lhe seja peculiar" (FINATTO, 2003, p. 203), desconstruindo-se, em meio às diversas tipologias existentes, a ideia de uma regra de definição uniforme, a definição baseada no modelo clássico de gênero próximo e diferença específica (GP DE), atualmente "reciclado" (FINATTO, 2003), continua sendo bastante produtiva e tendo um grande protagonismo nos trabalhos terminográficos.

Nesse modelo, recomenda-se que a definição terminológica seja iniciada com uma palavra de ancoragem ou superordenada (arquilexema ou metalexema), que designa um 
conceito genérico, e, em seguida, sejam apresentadas as particularidades do conceito a ser definido (O PAVEL, s.d.). O conceito, contudo, não deve ser descrito por si só, mas em relação a outros conceitos semelhantes, com algumas características comuns que os fazem pertencer a uma mesma classe e com algumas características em relação de oposição que os fazem diferentes entre si (CABRÉ, 1993).

Assim, as definições podem ser conduzidas tanto em função da presença quanto da ausência de determinadas características (traços sêmicos) (FINATTO, 2003; KRIEGER; FINATTO, 2004). As definições que são conduzidas em função da ausência de uma determinada característica denominam-se definições negativas.

Galdiano e Zavaglia (2015, p. 103) explicam que as defınições negativas "são classificadas com esse nome por definirem o termo pela ausência ou falta de algo, ou por exclusão de outros termos, com expressões do tipo $X=$ tudo o que não é $Y^{\prime \prime}$.

Casares (1950, p. 159 apud BARITÉ, 2016, p. 66) explica que a definição negativa é "aquela que, em vez de estabelecer os caracteres essenciais ${ }^{3}$ e acidentais de um objeto, realiza menções explícitas ao que esse objeto não é, ou faz referência a seu antônimo ou elementos ou atributos opostos.".

Na literatura sobre tipologia de definições de base lexicográfica, Ferreira (2005 apud PONTES, 2009, grifo nosso) entende a definição negativa como a definição antonímica exclusiva:

Definição antonímica inclusiva: ocorre quando o arquilexema possui sentido negativo. Por exemplo: "ce.go Privado da vista". (FERREIRA, 2001 apud PONTES, 2009, p. 181).

Definição antonímica exclusiva: também chamada de definição negativa, ocorre pela negação do antônimo da entrada. Por exemplo: "in.di.re.to Não direto".

Com base nessas definições, pode-se depreender que a definição negativa, em um sentido lato, não contém necessariamente uma frase negativa, com o uso explícito de um advérbio de negação, podendo ser construída por meio de expressões como: falta de, ausência de, contrário de, oposto de, privado de etc.

30 julgamento sobre o que é essencial e acessório depende do campo e dos objetivos da pesquisa terminológica (CABRÉ, 1993).

4 "[...] aquella que, en vez de establecer los caracteres esenciales y accidentales de un objeto, realiza menciones explícitas a lo que ese objeto no es, o hace referencia a su antónimo o a elementos o atributos opuestos. Como si se dijera que 'frío es lo contrario a caliente"'. 
Porém, de acordo com as convenções lexicográficas existentes, que também se aplicam à terminografia, a elaboração de uma definição deve ser orientada preferencialmente pela presença de determinadas características, e não pela ausência.

Essa orientação é corroborada por diversos autores (ISO, 1987; CABRÉ, 1993; ALPÍZARCASTILLO, 1997, DUBUC, 1999; ANDRADE, 2000; PAVEL; NOLET, 2002; BARROS, 2004; KRIEGER; FINATTO, 2004; ALMEIDA; PINO; SOUZA, 2007; PONTES, 2009; AZARIAN; TEBÉ, 2011; GALDIANO; ZAVAGLIA, 2015).

Azarian e Tebé (2011, p. 5), por exemplo, ao fazerem um compilado dos doze principais critérios para elaboração de definições nas normas espanholas (UNE 1-066 e UNE 1070), citam, dentre eles, as "características positivas", e confirmam ser este um requisito recomendado por consenso na literatura do âmbito, apontando como referências: Arnzt e Picht (1995), Cabré (1992) e Felber e Picht (1984). Ou seja, as características positivas são desejáveis e as negativas, indesejáveis.

Assim, em diversos trabalhos que versam sobre a definição terminológica, a definição negativa costuma ser incluída no rol dos defeitos a serem evitados, figurando ao lado da ambiguidade, da circularidade, da imprecisão, da incompletude, da prolixidade e da redundância (tautologia).

Dubuc (1999) a inclui entre a definição tautológica e a definição circular. Gapper (s.d., p. 82, grifo do autor), por sua vez, no Manual de gestión terminológica, a inclui entre a definição circular e a definição redundante, situando-a entre "os tipos de definição pouco recomendáveis para a maioria dos casos previstos no presentemanual". Ora, sea definição negativa é pouco recomendável para a maioria dos casos, haveria, por conseguinte, uma minoria de casos para os quais seria mais recomendável? Ou seja, existiriam exceções?

A recomendação reiterada na literatura, de fato, não é a de evitá-las sempre, mas a de evitá-las sempre que possível. Contudo, quase não se discutem ou ilustram os casos em que seriam aceitáveis ou até mais adequadas. A definição negativa também parece gerar certa contradição entre os autores, pois, após sua apresentação como um defeito, é comum encontrar, logo em seguida, uma argumentação no sentido contrário.

Dubuc (1999 apud BARITÉ, 2017), por exemplo, embora a coloque no rol dos defeitos, ao lado da tautologia e da circularidade, admite, no mesmo texto, que alguns conceitos científicos só podem ser definidos de forma negativa. Barité (2017), por sua vez, insere a definição negativa entre a circularidade negativa, a definição incompleta, a definição limitada e a tautologia. Não obstante, no mesmo tópico, cita o contra-argumento de Dubuc (1999), já mencionado, e de Casares (1950, p. 159), que não vê a definição negativa 
como um problema e inclusive afirma que é "recurso muito usado e não oferece grandes inconvenientes" ${ }^{\prime \prime}$.

Diante do exposto, vamos analisar, no próximo tópico, alguns casos de definições negativas com o propósito de verificar se há um fundamento para seu uso.

\section{Definições terminológicas negativas}

Os casos a serem analisados referem-se a um conjunto de definições formuladas por organismos científicos (União Internacional de Astronomia - UIA, Organização das Nações Unidas - ONU, Ministério do Turismo - MTUR, Agência Nacional de Vigilância Sanitária - ANVISA) e um conjunto de defınições formuladas em trabalhos terminográficos coordenados por linguistas.

\section{No discurso especializado}

Para ilustrar o uso e a pertinência da definição negativa, Barité (2016) utiliza a definição do termo planeta-anão, ao qual acrescentamos aqui mais duas definições correlatas, todas formuladas pela União Internacional de Astronomia (2006, p. 1, grifo nosso):

1. Um planeta é um corpo celeste que [a] está em órbita ao redor do sol, [b] tem massa suficiente para que sua própria gravidade supere as forças de corpo rígido de maneira que adquira um equilíbrio hidrostático (forma arredondada) e [c] limpou a vizinhança de sua órbita. ${ }^{6}$

2. Um "planeta anão" é um corpo celeste que [a] está em órbita ao redor do Sol, [b] tem massa suficiente para que a sua própria gravidade supere as forças de corpo rígido de maneira que adquira um equilíbrio hidrostático (forma arredondada), [c] não limpou a vizinhança da sua órbita e [d] não é um satélite. ${ }^{7}$

5 Casares (1950, p. 159) cita, como exemplo, o seguinte caso: "Ímpar". o que não é par ou não tem par.

6 No original: "A planet is a celestial body that is in orbit around the Sun, has sufficient mass for its self-gravity to overcome rigid body forces so that it assumes a hydrostatic equilibrium (nearly round) shape, and has cleared the neighborhood around its orbit".

7 No original: "A 'dwarf planet' is a celestial body that [a] is in orbit around the Sun, [b] has sufficient mass for its self-gravity to overcome rigid body forces so that it assumes a hydrostatic equilibrium (nearly round) shape, and [c] has not cleared the neighborhood around its orbit and [d] is not a satellite". 
3. Todos os outros objetos que orbitam o sol, excluídos os satélites, devem ser denominados coletivamente "pequenos corpos do sistema solar". 8

Comparando-se as definições de planeta (1) e planeta-anão (2), observa-se que, na definição (1), indicam-se os traços (a, b e c) e, na definição (2), indicam-se os traços (a) e (b) e a ausência do traço (c). Assim, a presença ou ausência do traço (c) é determinante para classificar um corpo celeste como um planeta ou um planeta-anão. Além disso, na definição (2), indica-se também, em (d), algo que o termo não é (recurso da exclusão).

Para Barité (2017), os dois enunciados negativos presentes na definição do termo planeta-anão (2) ("não limpou a vizinhança de sua órbita" e "não é um satélite") são pertinentes, pois estabelecem um diálogo necessário com as definições de dois outros termos (planeta e satélite) que, de tão próximos, poderiam com ele ser confundidos.

Diante disso, ele faz a seguinte reflexão: "[...] cabe aceitar, por exceção, que alguns dos enunciados de uma definição sejam negativos quando isso implica a necessidade de estabelecer definições distintivas correspondentes a elementos ou objetos próximos" (BARITÉ, 2017, p. 66).

Por outro lado, Barité (2017, p. 66, tradução nossa9) faz algumas restrições quanto a seu uso:

\begin{abstract}
Não parece aceitável, ao contrário, que a totalidade de uma definição seja construída com base em enunciados negativos, partindo-se do princípio de que todo objeto, material ou ideal, tem tipos, partes, materiais, propriedades, conformações e, portanto, pode ser definido com base em tais elementos ou aspectos.
\end{abstract}

Dessa forma, Barité (2017) defende que uma defınição poderia conter uma proposição negativa ou a indicação de um traço negativo (ausente), mas não deveria limitar-se a isso, ou seja, poderia eventualmente conter enunciados negativos (dizer o que o termo não é) desde que contivesse também enunciados positivos (dizer o que o termo é).

8 No original: "All other objects orbiting the Sun, excluded satellites, shall be referred to collectively as 'Small Solar System Bodies'".

9 No original: "Por lo expuesto cabe aceptar, por excepción, que algunos de los enunciados de una definición sean negativos cuando ello implica la necesidad de establecer definiciones distintivas correspondientes a elementos u objetos próximos. No parece de recibo, en cambio, que la totalidad de una definición sea construida en base a enunciados negativos, si se parte del principio de que todo objeto, material o ideal, tiene tipos, partes, materiales, propiedades, conformaciones, y por tanto admite ser definido en base a dichos elementos o aspectos". 
Em relação à definição (3), por meio de um processo de exclusão, os pequenos corpos do sistema solar são definidos como "todos os outros objetos que orbitam o sol que não sejam planetas, planetas-anões ou satélites", o que remete à fórmula de Galdiano e Zavaglia (2015, p. 103), que, aqui, poderia ser assim representada: $X=$ tudo o que não é $W$, Ye Z.

No exemplo a seguir, ao analisarem as definições de um glossário da área de Farmacovigilância, disponível no site da Anvisa, e sua adequação às convenções lexicográficas, Galdiano e Zavaglia (2015) relatam ter encontrado, em um conjunto de 52 definições, apenas duas definições negativas. Isso demonstra, primeiramente, que as definições negativas são, de fato, uma exceção (a minoria de Barité), ou seja, que, dentro de um conjunto sistematizado de definições, provavelmente existirá um número mais reduzido de definições negativas, seja por constituírem casos particulares, seja pelo esforço de evitá-las (sempre que possível). Vejamos as duas definições encontradas:

4. EVENTO ADVERSO NÃO GRAVE: Qualquer outro evento que não esteja incluído nos critérios de evento adverso grave. (ANVISA apud GALDIANO; ZAVAGLIA, 2015, p. 104, grifo nosso).

5. INEFETIVIDADE TERAPÊUTICA: Ausência ou a redução da resposta terapêutica esperada de um medicamento, sob as condições de uso prescritas ou indicadas em bula. (ANVISA apud GALDIANO; ZAVAGLIA, 2015, p. 104, grifo nosso).

No caso desses dois termos, Galdiano e Zavaglia (2015, p. 104) consideraram "compreensível que a definição escolhida tenha assumido um viés negativo, dado o próprio conceito representado por eles. A definição negativa, portanto, não nos parece inadequada, ao contrário, parece ter sido a mais apropriada para os termos em questão".

Esmiuçando os exemplos dados, veja-se que o sintagma terminológico evento adverso não grave (exemplo 4) apresenta, em sua própria estrutura, um advérbio de negação (em função de prefixo), como se fosse a redução de uma oração negativa: evento adverso não grave = evento adverso [que] não [é] grave. Nesse caso, o fato de o próprio termo que está sendo definido possuir um elemento de valor negativo em sua estrutura sintagmática deve justificar que sua definição contenha também uma oração negativa.

Ainda em relação ao exemplo (4), observa-se que, além de a definição conter uma oração negativa, o termo é definido por meio do recurso da exclusão, ou seja, todo evento adverso que não atenda os critérios para ser classificado como grave, por exclusão, é chamado de evento não grave, o que também remete à fórmula " $X$ = tudo o que não é $Y$ ", mencionada por Galdiano e Zavaglia (2015). 
Assim, o raciocínio da exclusão parece ser bastante produtivo, no meio científico, para definir e classificar os objetos, e isso se reflete na definição. No caso, de um determinado conjunto (eventos adversos) excluem-se determinados elementos (os graves), de forma que os elementos restantes compõem um subconjunto que representa o conceito designado pelo termo que está sendo definido (evento adverso não grave). Trata-se, assim, não só de uma definição negativa e definição por exclusão, mas também de uma variação da definição por extensão, consistindo esta na "enumeração dos entes a que se aplicaria uma designação" (FINATTO, 2003, p. 204). Entretanto, na impossibilidade de enumerar todos os entes particulares, utilizou-se uma fórmula.

Já no exemplo (5), o primeiro elemento do sintagma terminológico (inefetividade) é formado a partir do uso de um prefixo que denota negação/ausência (in-), ou seja, sem efetividade ou ausência de efetividade. Portanto, o próprio termo apresenta em sua estrutura morfológica um formante de valor negativo. Em relação à definição, a indicação da característica ausente dá-se por meio do uso da construção "ausência de".

Por meio desses exemplos, pode-se verificar que a definição negativa se mostra produtiva para definir termos que possuem elementos de valor negativo em sua estrutura morfológica e também quando se define um termo pelo mecanismo da exclusão.

O terceiro exemplo deste tópico refere-se à definição do termo turismo de aventura, proposta pelo Ministério do Turismo (BRASIL, 2006, p. 39, grifo nosso).

6. Turismo de Aventura: compreende os movimentos turísticos decorrentes da prática de atividades de aventura de caráter recreativo e não competitivo.

As atividades de aventura podem ser desenvolvidas para fins de recreação ou de competição. No turismo, essas atividades são estudadas/abordadas, no primeiro caso, no segmento do turismo de aventura e, no segundo caso, no segmento do turismo de esportes, que costumam ser confundidos. Por isso, observa-se que, na definição, não bastou dizer que no turismo de aventura as atividades são de caráter recreativo, sendo acrescentado, quase de forma redundante, que as atividades são de caráter não competitivo (recreativo e não competitivo). Essa ênfase é explicada pelo fato de ser necessário, nesse discurso de especialidade, marcar a diferença entre os dois termos que podem ser facilmente confundidos, turismo de aventura (não competitivo) e turismo de esportes (competitivo).

Como último exemplo desta seção, segue a definição do termo saúde, formulada no documento de constituição da Organização Mundial da Saúde (ONU, 1946, p. 1). 
7. um estado de completo bem-estar físico, mental e social e não somente ausência de afecções e enfermidades.

O conceito de saúde, por muito tempo, foi definido apenas como ausência de afecções ou enfermidades. Em 1946, como pode ser observado em (7), tal conceito ampliou-se. Entretanto, para os especialistas, representados aqui pela ONU/OMS, ainda se fazia necessário explicitar que a saúde não deveria mais ser vista somente como a ausência de doenças. Em outras palavras, no discurso científico da época, foi necessário deixar expresso no enunciado definitório a mudança de paradigma em relação ao que se passou a entender por saúde e a limitação da definição anterior. ${ }^{10}$

Nesse ponto, parece-nos bastante apropriada esta reflexão de Almeida, Souza e Pino (2007, p. 7), entremeada por uma citação de Desmet (2002, p. 182):

[...] cada vez mais é necessário admitir a presença de um sujeito enunciador no texto definitório, haja vista que determinados fenômenos que ocorrem na DT [definição terminológica] só podem ser explicados à luz da enunciação. Ou ainda como afirma Desmet (2002: 182), "[...] os termos, como qualquer signo linguístico, não podem ser definidos fora dos seus usos por parte dos locutores e fora de aplicações específicas".

Os casos ilustrados até agora abordaram definições elaboradas por organismos especializados (UIA, ONU/OMS e ANVISA), que não necessariamente pautaram-se nas convenções léxico-terminográficas. Porém, esses exemplos mostram que, na prática, os especialistas, principais locutores do discurso científico, parecem se utilizar, algumas vezes, das definições negativas. Os exemplos da seção seguinte são de outro tipo: foram elaborados no âmbito de trabalhos terminográficos e, portanto, à luz das convenções léxico-terminográficas.

\section{Em trabalhos terminográficos}

Ao tratarem da definição terminológica nos dicionários especializados, Almeida, Souza e Pino (2007) também citam os três defeitos elencados por Dubuc (1999) e, em seguida, comentam que o autor admite que alguns conceitos científicos só podem ser definidos de forma negativa.

Nesse ponto, a título de ilustração, Almeida, Souza e Pino (2007, p. 5) citam duas definições negativas, extraídas do Dicionário de Revestimento Cerâmico (DiRC), desenvolvido no âmbito do Grupo de Estudos e Pesquisas em Terminologia (GETerm) ${ }^{11}$, a saber:

10 Atualmente, essa definição também é questionada por ser considerada utópica.

11 Grupo de estudos coordenado por Gladis Maria de Barcellos Almeida, vinculado ao Departamento de Letras da Universidade Federal de São Carlos. 
8. Empeno: defeito em que há a falta de planaridade da placa cerâmica, marcado pelo desvio de pelo menos um vértice em relação ao plano estabelecido pelos outros três, o qual ocorre devido à diferença de retração entre o vidrado e o suporte durante o resfriamento da placa ou pelas condições de queima do produto.

9; Trapézio: defeito no qual a placa cerâmica não apresenta os lados perpendiculares, ou seja, caracteriza-se pelos ângulos internos diferentes de noventa graus. Pode estar associado à formulação ou à preparação da massa cerâmica, à prensagem ou à queima.

No exemplo (8), a definição do termo "empeno" começa com o descritor "defeito" seguido de pronome relativo (em que) e indicação de uma característica ausente (planaridade) por meio da expressão "falta de". No exemplo (9), a definição do termo "trapézio" começa com o mesmo descritor, "defeito", seguido de pronome relativo (no qual) e de uma oração negativa que indica também a ausência de uma característica (lados perpendiculares).

Observa-se que a definição negativa se mostra adequada e necessária para descrever tipos de defeito. A palavra "defeito" possui um sentido negativo (imperfeição, incorreção, falha, deformidade), referindo-se a qualquer desvio de uma característica de um item em relação ao seu ideal.

No caso acima, as características ideais de uma placa cerâmica são a planaridade e a perpendicularidade. Os defeitos se referem justamente ao desvio em relação a essas características específicas, ou seja, falta de planaridade e de perpendicularidade. A definição negativa parece ser apropriada, então, nos casos em que a essência do conceito consiste exatamente na ausência de uma característica essencial do objeto ideal.

Ao se analisar de forma mais atenta essa definição, verifica-se que seria possível eliminar a parte negativa (não apresenta lados perpendiculares) que a compõe (9) e reduzi-la à paráfrase: "defeito no qual a placa cerâmica apresenta ângulos internos diferentes de noventa graus". Porém, a expressão "lados perpendiculares" (referente à característica ausente) parece expressar um conceito bastante conhecido e um traço sêmico muito relevante que, embora ausente, é o ideal a ser alcançado, e não deveria ser excluída da definição por conta de ter de atender uma recomendação.

Além disso, observa-se que não há muita diferença para a compreensão do conceito utilizar a frase "a placa apresenta ângulos internos diferentes de noventa graus" em vez de "a placa não apresenta ângulos internos de noventa graus/lados perpendiculares".

É válido concluir, portanto, que a definição negativa não somente é, de fato, utilizada, como pode ser bastante adequada para definir conceitos que possuem um valor/teor/ sentido negativo, tais como: defeitos, deficiências, desordens, disfunções, ineficiências, 
doenças etc., especialmente quando gerados pela falta de algo que deveria estar presente ou pelo desvio em relação a algo considerado ideal.

A definição negativa, com efeito, é um recurso eficaz e profícuo na conceituação de doenças. Vários exemplos podem ser observados no Dicionário de Dermatologia de Barros (2009).

Nessa obra, foram utilizados enunciados negativos nos casos em que a característica central de uma patologia era a ausência de algo, por exemplo: acromia (ausência de pigmento melânico cutâneo), albinismo (ausência de tirosinase, ausência de melanina), alopecia (ausência do folículo piloso); aplasia (desenvolvimento incompleto ou ausência da epiderme); anidrose (ausência ou deficiência total ou parcial da secreção de suor), anoníquia (ausência de unhas), genodermatose atrófica (ausência de crescimento ou do desenvolvimento de algum órgão do corpo), lipodistrofia (ausência quase total de gordura subcutânea), poliose (ausência de pigmento nos pelos), entre outros. Seguem exemplos:

10. acromia: S. f. discromia de origem hereditária, congênita ou adquirida. Caracteriza-se pela ausência total de pigmento melânico cutâneo, provocando o aparecimento de manchas brancas na pele, em razão de alguns tecidos ou células não aceitarem a presença de corantes. [...]. (BARROS, 2004, p. 98).

11. albinismo: S. m. acromia congênita ou hereditária de caráter autossômico recessivo, causada por bloqueio metabólico na produção de melanina, devido à ausência parcial ou total de tirosinase. Caracteriza-se pela ausência de melanina na pele, cabelos, pêlos, estruturas oculares (olhos, corótide e íris), podendo provocar fotofobismo e movimentos rítmicos de contração e dilatação da pupila (nistagmo). [.... (BARROS, 2004, p. 103).

Nesses casos, a doença é causada exatamente pela falta ou deficiência de algo, parecendo, portanto, aceitável e adequado que a definição seja construída em torno de uma característica ausente. Contudo, nota-se que as definições desses termos, conforme preceitua Barité (2006), não se limitam à indicação da ausência de uma característica, mas indicam também as características presentes. O enunciado negativo, portanto, é um elemento da definição terminológica que a complementa.

Foram também utilizados enunciados negativos para indicar a ausência de algumas manifestações clínicas, já que a presença ou a ausência delas são fundamentais para o diagnóstico diferencial, isto é, para diferenciar uma doença de outra similar e chegar a um diagnóstico. 0 estudo das definições abaixo pode ilustrar o que foi dito: 
12. infiltrado linfocítico de Jessner-Kanol: S. m. pseudolinfoma de causa desconhecida. Os achados histopatológicos consistem em infiltrado linfocitário fundamentalmente constituído por células T, em disposição perianexial e perivascular na pele. Não são observadas alterações na epiderme. Caracteriza-se pelo aparecimento de lesões discoides eritematosas, em geral com tendência a clareamento central e crescimento centrífugo. As lesões apresentam superfície lisa e não ocorre hiperqueratose folicular. A ausência de atrofia, de hiperqueratose folicular, de degeneração hidrópica na basal, de globulinas e de complemento na junção dermepidérmica podem determinar o diagnóstico. Localiza-se mais frequentemente na face, sobretudo na fronte, nas regiões malares, nas têmporas, nas orelhas e na porção superior do dorso. Alguns autores consideram o infiltrado linfocítico de Jessner-Kanol como entidade autônoma, enquanto que outros o consideram como uma forma de lúpus eritematoso discoide. [...]. (BARROS, 2004, p. 264).

13. calosidade: S. f. afecção dos pés causada por fricção, sapatos inadequados, vícios de postura ou situações ortopédicas, como pé chato, fratura e artrite. Diferencia-se do calo por não apresentar porção central homogênea e ser menos focal. É dura, pouco elevada, inelástica, ocorrendo ocasionalmente fissura. É de coloração amarelada e possui limites imprecisos. É dolorosa, pouco sensível, podendo dar espaço a manifestação de outras infecções. Localiza-se nos pés e mãos, em áreas de pressão ou fricção. [.... (BARROS, 2004, p. 131).

Como o Dicionário de Dermatologia é uma obra muito ampla, não é possível analisar e sistematizar aqui todos os casos, mas vale citar, ainda, a ocorrência de formas/estruturas negativas quando da indicação de uma determinada manifestação clínica que pode estar presente ou não:

14. abscesso2: S. m. piodermite causada por estreptococos e, eventualmente, por estafilococos. É um quadro agudo, caracterizado pelo aparecimento de edema flutuante, circunscrito e mais ou menos pronunciado, que tende à supuração. A lesão tem tamanho variável e pode estar acompanhada de eritema, calor e dor (abscessos quentes) ou não (abscessos frios). São observados, ainda, fenômenos gerais, como febre, calafrios e vômitos. Atinge a hipoderme, localizando-se no interior de um tecido, órgão ou qualquer região do corpo. [...]. (BARROS, 2004, p. 91).

15. paniculite: S. f. dermatose caracterizada por uma inflamação do panículo adiposo subcutâneo. Apresenta nódulos ou eritemas violáceos que podem ou não evoluir para ulceração. As lesões localizam-se na hipoderme, mais frequentemente nas pernas e no abdômen. [...]. (BARROS, 2004, p. 325).

Também foi frequente, em outras definições do Dicionário de Dermatologia, a utilização do advérbio de negação "não", na função prefixal, para indicar características em relação 
de oposição: (não) alérgico, (não) ceratósica, (não) congênita, (não) coalescente, (não) contagiosa, (não) corneificada, (não) cicatricial, (não) depressível, (não) destrutivo, (não) doloroso, (não) elevado, (não) específico, (não) escamoso, (não) gonocócico, (não) hereditário, (não) hormonal, (não) infeccioso, (não) inflamatório, (não) invasivo, (não) marginado, (não) medulado, (não) mielinizado, (não) nítido, (não) pruriginoso, (não) prurítico, (não) purulento, (não) putrefativo, (não) sexual, (não) supurativo. Para comprovar essa afırmação, são apresentados os seguintes exemplos:

16. queilite glandular: S. f. afeç̧ão das mucosas causada por inflamação e aumento das glândulas salivares heterotróficas nos lábios. Pode ter origem congênita ou genética. Apresenta ulceração, edema, hiperplasia da glândula mucosa, formação de crostas, trajetos fistuloso e abscessos. Apresenta forma inflamatória e não inflamatória. [...]. (BARROS, 2004, p. 362).

17. paniculite nodular não supurativa febril recidivante: S. f. hipodermite de causa desconhecida, podendo ser resposta a vários estímulos agressivos. Apresenta surtos febris e recidivantes de nódulos ou placas subcutâneas adiposas inflamadas e eritematosas. Os nódulos são vermelhos ou azulados, não supurativos, dolorosos, profundos e móveis. [...]. Localiza-se, preferentemente, nos membros inferiores e tronco e, com menos frequência, nos braços e face. [...]. (BARROS, 2004, p. 326).

Por último, vejamos alguns exemplos de definições obtidos em uma pesquisa terminográfica que teve como objeto de estudo conjuntos terminológicos relacionados ao turismo. Em um conjunto de definições elaboradas por orientandos vinculados à pesquisa, observaram-se as seguintes defınições negativas:

18. no-show $[\mathrm{HOT}$.] m. não comparecimento do hóspede ao meio de hospedagem em que fez uma reserva, podendo ou não ser cobrado o valor da primeira diária.

19. garantia de no-show [HOT.] f. pagamento adiantado da primeira diária que pode ser cobrado em caso de não comparecimento do hóspede.

Cabe apontar, primeiramente, que todas as definições e todos os contextos definitórios do termo "no-show", extraídos do corpus da referida pesquisa e registrados na ficha terminológica, continham formas/estruturas negativas: 
Quadro 1. Definições e contextos definitórios

No show: reserva que não chegou, que poderá ou não ser cobrada do cliente. (Apostila Gerência de Hospedagem, 2013).

No show: não-comparecimento do hóspede. (Cartilha Hotelaria e Hospitalidade, BRASIL, 2007).

No-show: não comparecimento de um hóspede em um hotel. (Perfil de Negócios de Hotelaria (Hotéis e Pousadas) (SEBRAE, 2014).

No show: Expressão de origem americana usada para designar o hóspede ou passageiro que não se apresenta no hotel ou meio de transporte na data ou no momento para os quais havia reservado lugar, o depósito efetuado, normalmente de uma diária, é então perdido. (Dicionário de Turismo, BRAGA, 2003).

No show: Expressão de origem americana usada para designar o hóspede ou passageiro que não se apresenta no hotel ou meio de transporte a data ou momento para os quais havia reservado lugar, o depósito efetuado, normalmente de uma diária, é então perdido. (Dicionário Brasileiro de Turismo, FERREIRA, 1975).

No show: Termo muito utilizado em hotelaria e aviação, que significa o não-comparecimento do hóspede no hotel mesmo tendo reserva e/ou não-comparecimento do passageiro de avião para embarque. (Glossário técnico: gastronômico, hoteleiro e turístico, VIERA; CÂNDIDO, 2003).

Fonte: Dias (2018)

Observa-se que, em todas as fontes consultadas (apostila, cartilha, manual, dicionários e glossário), o termo no-show é definido por meio de uma definição negativa. Como já foi discutido, o termo no-show apresenta, em sua própria estrutura, um elemento com sentido negativo (no). Além disso, é usado em uma situação que pode ser considerada negativa para o meio de hospedagem, visto que a situação ideal (chegada do hóspede) não se realiza. Essas condições parecem predispor à escrita da definição por meio de formas negativas.

Além disso, na segunda parte do enunciado definitório, há a indicação de um traço que pode ou não estar presente (cobrança da primeira diária), o que também parece gerar uma predisposição às formas negativas.

Também foram encontrados casos em que a oração negativa poderia ser reformulada por meio do uso da preposição sem (hóspede sem reserva e hóspede sem dinheiro).

20. walk-in [HOT.] m. hóspede que não efetuou reserva. 
21. paid-out [HOT.] m. empréstimo que o hotel concede ao hóspede que não possui dinheiro em mãos para que ele consiga comprar algo.

Há também casos em que o advérbio não é usado com função prefixal para modificar adjetivos que ajudam a descrever o conceito:

22. CHD [HOT.] f. Abreviação utilizada para descrever crianças de 2 a 11 anos ou criança não pagante. (DIAS, 2018).

23. mountain bike [Ativ.] $\mathrm{m}$. realização de percurso em trilhas ou estradas não pavimentadas em bicicletas especiais para este fim (mountain bikes). (SANTOS, 2016, p. 73).

Dentro desse mesmo projeto, foi observado o caso referente às unidades de conservação, que são divididas em quatro unidades de proteção integral e sete unidades de uso sustentável. Seguem dois exemplos de definição, um de cada categoria.

24. estação ecológica unidade de conservação de proteção integral, de posse e domínio público, que tem como objetivo a preservação da natureza e a realização de pesquisas científicas, devidamente autorizadas, não admitindo ocupação humana e nem visitação pública, exceto para fins educacionais, permitindo alterações apenas em caso de restauração de ecossistemas, manejo de espécies para preservação da diversidade biológica, pesquisas e coletas com finalidade científica. Var.: ESEC, EE. (PEREIRA; DELVIZIO; BUENO, 2019, p. 331).

25. reserva particular do patrimônio natural unidade de conservação de uso sustentável de domínio privado que tem como objetivo conservar ou recuperar valores naturais nativos ou semi primitivos de grande beleza cênica e de grande importância para a preservação do ciclo biológico da flora e da fauna nativas, admitindo ocupação humana, visitação pública com objetivos turísticos, recreativos e educacionais e pesquisa científica. Var.: RP. (PEREIRA; DELVIZIO; BUENO, 2019, p. 334).

Nota-se, nesse conjunto, o uso de frases negativas para indicar a possibilidade ou não do uso da unidade para ocupação humana e visitação, contrastando especialmente as duas categorias de unidades de conservação em relação a esses traços (ocupação humana e visitação).

\section{Conclusão}

Esse artigo teve como objetivo primeiro contribuir para os estudos em Terminologia e Terminografia, uma vez que aborda o conceito de definição negativa, cujo estudo e 
análise são ainda escassos. Diante da recomendação de se evitar as definições negativas sempre que possível e do fato de tais definições serem pouco discutidas e ilustradas na literatura científica da área, sendo geralmente inseridas ao lado dos defeitos a serem evitados, foi compilado um conjunto de definições negativas, encontradas tanto em trabalhos terminográficos quanto no discurso especializado, com o intuito de identificar alguns fundamentos ou padrões para seu uso.

Primeiramente, observou-se que o termo definição negativa, nos estudos terminológicos, refere-se a um tipo de definição no qual se indica algo que o termo não é, não tem ou o que Ihe falta, por meio de frases negativas (não é, não apresenta), de fórmulas de exclusão ( $x$ = tudo o que não é y) ou de expressões/palavras de valor negativo (falta de, ausência de, desprovido de, sem), sem se limitar necessariamente à indicação das características ausentes.

O traço sêmico ausente pode se referir à caraterística central em torno da qual se constrói o conceito (por exemplo, doença causada pela falta de algo), a uma característica secundária (por exemplo, uma característica da lesão apresentada pela doença definida) ou a uma característica diferencial, que está presente ou ausente em termos (e conceitos) em relação de oposição (por exemplo, um diagnóstico diferencial entre duas doenças similares com base na presença ou ausência de um sintoma).

Em geral, os seguintes casos, que podem estar, inclusive, sobrepostos, parecem justificar o uso de uma definição negativa:

a) definição de termos que designam conceitos determinados pela ausência de uma característica ou pelo desvio em relação à característica considerada ideal;

b) definição de termos que expressam um conceito de valor negativo (defeito, desordem, desvio, disfunção, doença etc.);

c) definição de termos que possuem um elemento de valor negativo em sua própria estrutura morfológica;

d) estabelecimento de definições distintivas correspondentes a objetos próximos;

e) indicação de traços em relação de oposição por meio de palavras formadas a partir do advérbio (pseudoprefixo) não.

Conforme demonstrado por esta pesquisa, a definição negativa ocorre em um número reduzido, porém significativo, de casos. Ao se realizar uma análise detalhada das redações das definições negativas combinada com o estudo do valor semântico dos termos assim definidos, constata-se que a definição negativa não deveria figurar ao lado dos vícios e defeitos, mas ao lado de outros tipos de definição dos quais o terminólogo pode fazer uso, respaldado por uma teoria comunicativa da Terminologia e pelo gradual alinhamento dos construtos teóricos sobre a definição terminológica a esta teoria. 
Assim, se diversos pesquisadores renomados admitem a necessidade da definição terminológica negativa em casos particulares e, inclusive, usam-nas em seus trabalhos, por que continuar inserindo-a no rol dos defeitos a serem evitados (sempre que possível)? Seria a definição terminológica negativa um mal necessário ou mais um recurso à disposição dos terminólogos?

\section{REFERÊNCIAS}

ALMEIDA, G. M. B.; PINO, D. H. P.; SOUZA, D. S. L. A definição nos dicionários especializados: proposta terminológica. Debate Terminológico, v. 3, 2007. Disponível em: https://seer.ufrgs.br/riterm/article/view/23812. Acesso em: 30 set. 2020.

ALPÍZAR-CASTILLO, R. Cómo hacer un diccionario científico técnico. Buenos Aires: Editorial Memphis, 1997.

ANDRADE, M. M. Conceito/definição em dicionários da língua geral e em dicionários de linguagens de especialidade. Cadernos do CNLF, Rio de Janeiro, v. 1, n. 10, 2000 [não paginado].

ARNTZ, R.; PICHT, H. Introducción a la terminología. Madrid: Fundación Germán Sánchez Ruipérez,1995.

AZARIAN, J.; TEBÉ, C. La metodología de elaboración de definiciones terminológicas en vocabularios normalizados: análisis en normas UNE. Debate Terminológico, n. 7, p. 2-23, abr. 2011. Disponível em: https://seer.ufrgs.br/riterm/article/view/20710. Acesso em: 30 set. 2020.

BARITÉ, M. La definición en terminología. In: ÁLVAREZ CATALÁ, S.; BARITÉ, M. (coords.). Teoría y práxis en terminología. Montevidéu: Universidad de la República, 2017. Disponível em: https://www.csic.edu.uy/sites/csic/files/barite_teoria_y_praxis_en_terminologia_fic. pdf. Acesso em: 30 set. 2020.

BARROS, L. A. (coord.). Dicionário de Dermatologia. São Paulo: Cultura Acadêmica, 2009. Disponível em: http://www.culturaacademica.com.br/catalogo/dicionario-dedermatologia/. Acesso em: 30 set. 2020.

BARROS, L. A. Curso básico de terminologia. São Paulo: EDUSP, 2004. 
BRASIL. Ministério do Turismo. Marcos conceituais do turismo. Brasília, 2006. Disponível em: http://www.turismo.gov.br/sites/default/turismo/o_ministerio/publicacoes/ downloads_publicacoes/Marcos_Conceituais.pdf. Acesso em: 2006.

CABRÉ, M. T. La terminología: Representación y comunicación. Barcelona, Institut Universitari de Lingüistica Aplicada, Universitat Pompeu Fabra, 1999.

CABRÉ, M. T. La terminología: teoría, metodología, aplicaciones. Tradução de Carles Tebé. Barcelona: Editorial Antártida/Empúries, 1993.

CABRÉ, M. T. La terminologia: la teoria, els mètodes, les aplicacions. Barcelona: Empúries, 1992.

DESMET, I. A análise do sentido em terminologia: teoria e prática da definição terminológica. Tradterm, v. 8, p. 169-188, 2002. Disponível em: http://www.revistas.usp. br/tradterm/article/view/49129. Acesso em: 30 set. 2020.

DIAS, C. Elaboração de definições e busca de equivalentes em inglês para um conjunto de termos da hotelaria. 2018. Trabalho de Conclusão de Curso (Graduação em Turismo) Câmpus Experimental de Rosana, Universidade Estadual Paulista "Júlio de Mesquita Filho", Rosana, 2018.

DUBUC, R. Manual práctico de terminología. Chile: RiL Editores, 1999.

FELBER, H.; PICHT, H. Métodos de terminografía y principios de investigación terminológica. Madrid: Instituto Miguel de Cervantes-CSIC, 1984.

FINATTO, M. J. B. A definição de termos técnico-científicos no âmbito dos estudos de terminologia. Revista de Estudos da Linguagem, Belo Horizonte, v. 11, n. 1, p. 197-222, jan./jun. 2003. Disponível em: http://periodicos.letras.ufmg.br/index.php/relin/article/ view/2351. Acesso em: 30 set. 2020.

GALDIANO, I.; ZAVAGLIA, C. A definição terminológica em um glossário da Farmacovigilância: algumas considerações. Revista GTLex, v. 1, n. 1, p. 91-109, 2015. Disponível em: http://www.seer.ufu.br/index.php/GTLex/article/view/31748. Acesso em: 30 set. 2020.

GAPPER, S. E. Manual de gestión terminológica. Heredia, Costa Rica: EUNA, 2008 
INTERNATIONAL UNION OF ASTRONOMY. Resolution B5. Definition of a planet in the solar system. 2006. Disponível em: https://www.iau.org/static/resolutions/Resolution_ GA26-5-6.pdf. Acesso em: 30 set. 2020.

ISO 1087. Terminology work: vocabulary. Part 1: Theory and application, 2000.

ISO 704. International Standard. Principles and methods of terminology. Switzerland, 1987.

KRIEGER, M.; FINATTO, M. J. B. Introdução à Terminologia: teoria e prática. São Paulo: Contexto, 2004.

O PAVEL: curso interativo de terminologia. Disponível em: http://www.termium.gc.ca/ didacticiel_tutorial/portugues/lecon3/page3_5_3_p.html. Acesso em: 15 jan. 2020.

ORGANIZAÇÃO DAS NAÇÕES UNIDAS. Constituição da Organização Mundial da Saúde (OMS/WHO). 1946. Disponível em: http://www. direitoshumanos.usp.br/index.php/ OMS-Organizacao-Mundial-da-Saude/constituicao-da-organizacao-mundial-da-saudeomswho.html. Acesso em: 30 set. 2020.

PAVEL, S.; NOLET D. Manual de Terminologia. Tradução de Enilde Faulstich. Ottawa: Public Works and Government Services Canada, 2002. Disponível em: https:// linguisticadocumentaria.files.wordpress.com/2011/03/pavel-terminologia.pdf. Acesso em: 30 set. 2020 .

PEREIRA, B. S.; DELVIZIO, I. A.; BUENO, F. P. Unidade de conservação: um termo brasileiro para áreas naturais protegidas. In: TAVARES, G. (org.). Turismo, lazer e negócios. Ponta Grossa: Atena, 2019. p. 320-337. Disponível em: https://www. atenaeditora.com.br/wp-content/uploads/2019/05/e-book-Turismo-Lazer-e-Negocios. pdf. Acesso em: 30 set. 2020.

PONTES, A. L. Dicionário para uso escolar: o que é como se lê. Fortaleza: EdUECE, 2009.

SAGER, J. C. Curso práctico sobre el procesamiento de la terminología. Madrid: Pirámide, 1993.

SANTOS, P. S. S. Proposta de modelo de definição para os termos referentes às atividades de aventura. 2016. Trabalho de Conclusão de Curso (Graduação em Turismo) - Câmpus Experimental de Rosana, Universidade Estadual Paulista "Júlio de Mesquita Filho", Rosana, 2016. 